NBER WORKING PAPER SERIES

\title{
EVALUATING THE CALVO MODEL OF STICKY PRICES
}

\author{
Martin Eichenbaum \\ Jonas D.M. Fisher \\ Working Paper 10617 \\ http://www.nber.org/papers/w10617 \\ NATIONAL BUREAU OF ECONOMIC RESEARCH \\ 1050 Massachusetts Avenue \\ Cambridge, MA 02138 \\ June 2004
}

We thank Lawrence Christiano for helpful conversations. The views expressed herein are those of the authors and not necessarily those of the Federal Reserve System or the Federal Reserve Bank of Chicago. The views expressed herein are those of the author(s) and not necessarily those of the National Bureau of Economic Research.

(C2004 by Martin Eichenbaum and Jonas D.M. Fisher. All rights reserved. Short sections of text, not to exceed two paragraphs, may be quoted without explicit permission provided that full credit, including (C) notice, is given to the source. 
Evaluating the Calvo Model of Sticky Prices

Martin Eichenbaum and Jonas D.M. Fisher

NBER Working Paper No. 10617

June 2004

JEL No. E0, E1, E3

\title{
$\underline{\text { ABSTRACT }}$
}

Can variants of the classic Calvo (1983) model of sticky prices account for the statistical behavior of post-war US inflation? We develop and test versions of the model for which the answer to this question is yes. We then investigate whether these models imply plausible degrees of inertia in price setting behavior by firms. We find that they do, but only if we depart from two auxiliary assumptions made in standard expositions of the Calvo model. These assumptions are that monopolistically competitive firms face a constant elasticity of demand and capital can be instantaneously reallocated after a shock. When we modify these assumptions our model is consistent with the view that firms re-optimize prices, on average, once every two quarters.

\author{
Martin Eichenbaum \\ Department of Economics \\ Northwestern University \\ 2003 Sheridan Road \\ Evanston, IL 60208 \\ and NBER \\ eich@northwestern.edu \\ Jonas D.M. Fisher \\ Federal Reserve Bank of Chicago \\ jfisher@frbchi.org
}




\section{Introduction}

This paper addresses two questions. First, can variants of the Calvo (1983) sticky price model account for the statistical behavior of post-war U.S. inflation rates? Second, can these models succeed statistically with plausible degrees of inertia in pricing setting behavior at the firm level? Our answer to the first question is yes. Our answer to the second question is also yes, but only if we depart from two auxiliary assumptions made in standard expositions of the Calvo model. These assumptions are that monopolistically competitive firms face a constant elasticity of demand and capital is not firm-specific. Under these assumptions, our estimated model implies that firms re-optimize prices roughly once every two years. This finding motivates us to consider a variant of the model in which the elasticity of demand facing firms is variable and capital is firm-specific. The resulting model is observationally equivalent to the original model in terms of its implications for the aggregate time series used in our analysis. However, inference about how frequently firms re-optimize prices is affected in an important way. This model is consistent with the view that firms re-optimize prices on average once every two quarters.

Despite ongoing controversies, models embodying sticky prices continue to play a central role in analyses of the monetary transmission mechanism. In time-dependent sticky price models, the number of firms that change prices in any given period is specified exogenously. ${ }^{1}$ In state-dependent pricing models, the number of firms changing prices in any given period is determined endogenously. ${ }^{2}$ While state-dependent models seem promising (at least to us) they are substantially more difficult to work with than time-dependent models. Perhaps more importantly, empirically plausible versions of time and state-dependent models often generate similar results for many policy experiments that are relevant in moderate inflation economies. ${ }^{3}$ Here we take as given the widespread interest in time-dependent models and

\footnotetext{
${ }^{1}$ Classic models of this sort were developed by Taylor (1980) and Calvo (1983). Modern variants are now central elements of a large class of models. See, for example, Christiano, Eichenbaum and Evans (2004), Erceg, Henderson and Levon (2000), Gali and Gertler (1999), Rotemberg and Woodford (1997) and Yun (1996).

${ }^{2}$ Important recent examples of state-dependent pricing models include Dotsey, King and Wolman (1999), Burstein (2003) and Golosov and Lucas (2003).

${ }^{3}$ See, for example, Burstein (2002) and Klenow and Krystov (2003). In contrast, Golosov and Lucas (2003) argue that the shock repsonses in their model are very different from the analog responses in a Calvotype model. It is not clear whether this would be the case in a version of the Golosov and Lucas model calibrated to the finding in Klenow and Krystov (2003) that $90 \%$ of monthly US inflation stems solely from fluctuations in the average size of price changes, as opposed to the fraction of firms who change prices.
} 
focus on the empirical properties of Calvo-style models.

We interpret the Calvo price-setting mechanism as capturing firms' responses to various costs of changing prices. The basic idea is that in the presence of these costs, firms fully optimize prices only periodically, and follow simple rules for changing their prices at other times. The type of costs we have in mind are those associated with optimization (e.g., costs associated with information gathering, decision making, negotiation and communication). These costs are different from menu costs, which apply to all price changes. ${ }^{4}$ Consequently, we estimate and test variants of Calvo-style models where firms, who do not re-optimize their prices, index their price either to the unconditional rate of inflation (static indexation) or lagged inflation (dynamic indexation). In addition, we allow for the possibility that there is a lag between the time at which firms re-optimize their price plans and the time at which they implement the new plan. In our model, this lag is equivalent to the assumption that firms re-optimize time prices based on an information set that only includes lagged values of marginal cost. For convenience, we proceed under the "implementation lag" interpretation.

Our main statistical findings can be summarized as follows. First, we find strong evidence against the model if we assume that firms instantly implement new price plans. This finding is true for both the static and dynamic indexation versions of the model. However, when we allow for a one-period implementation lag of new pricing plans, neither the static nor dynamic indexation versions of the model can be rejected using conventional statistical tests. Interestingly, this is the specification of the Calvo model adopted in Galí and Gertler (1999) and Christiano, Eichenbaum and Evans (2004), among others.

Standard tests of the model's over-identifying restrictions may have low power against specific alternatives. Galí and Gertler (1999) argue this is the case when the Calvo model is confronted with the possibility that some firms adopt backward-looking rules of thumb for setting prices. Consistent with Galí and Gertler (1999), we find evidence against the hypothesis that there are no rule-of-thumb firms if we assume that optimizing firms adopt a static indexation rule. However, we find virtually no evidence against this hypothesis if we assume that optimizing firms adopt a dynamic indexation rule.

Evidently, allowing for a one-quarter delay in the implementation of new prices and dynamic indexation renders the standard Calvo model consistent with the aggregate data

\footnotetext{
${ }^{4}$ Zbaracki, Ritson, Levy, Dutta and Bergen (2000) provide some microeconomic evidence that costs associated with reoptimization are much more important than menu costs.
} 
in a statistical sense. But that does not mean the estimated model makes economic sense. Here, the key question is whether the model implies plausible inertia in price setting behavior by firms. Taken at face value, the answer to this question is no. Specifically, the estimated version of our preferred model implies that firms re-optimize prices, on average, roughly once every two years. This implication seems implausible to us and would justify rejection of the Calvo model.

As it turns out, this inference about price inertia at the firm level is warranted only under very special auxiliary assumptions associated with the Calvo model; namely, that price setting firms face a constant elasticity of demand and capital is not firm-specific. Following Kimball (1995), we allow for the possibility that the elasticity of demand is increasing in a firm's price. In addition, we follow Woodford (2003) and allow for the possibility that capital is firm-specific. In this specification, a firm's capital can only be augmented with a one-period delay using final goods, subject to adjustment costs. For reasons discussed below, each of these extensions enable the Calvo model to account for the dynamics of inflation with lower degrees of price rigidity.

We demonstrate that the parameters of the extended Calvo model are not separately identified using aggregate time series data. In particular, one cannot separately identify the probability that a firm re-optimizes its price, the nature of demand elasticities, and the degree of capital mobility. Still, we can identify the frequency of re-optimization if we have information about demand elasticities and the degree of capital mobility.

If we assume that capital is firm-specific and there are modest costs of adjusting capital, then the model implies a degree of inertia in price re-optimization that is much more plausible than that implied by the benchmark Calvo model. Depending on our assumptions about demand elasticities, our measure of inflation, and the sample period under consideration, we infer that firms re-optimize prices between once every 2.3 and 3.0 quarters. In no case can we reject, at conventional confidence intervals, the hypothesis that firms re-optimize prices once every 1.8 quarters. While there are ambiguities involved in the comparison, this result renders our model consistent with the micro evidence discussed in Klenow and Krystov (2003) and Golosov and Lucas (2003).

The rest of the paper is organized as follows. Section 2 discusses our extended version of the Calvo model. In Section 3 we display our econometric strategy for testing the model, including the variant that allows for rule-of-thumb firms. Section 4 discusses the data that 
we use. Section 5 presents our statistical results. In Section 6 we interpret the parameters of the estimated model. Finally, Section 7 contains brief concluding remarks.

\section{The Calvo Model of Sticky Prices}

In this section we display an extended version of the Calvo model. In the first subsection we consider a version of the model in which intermediate good firms face a non-constant elasticity of demand for their output. In addition, we allow for a finite lag between the time

firms re-optimize prices and when they implement new plans. In the second subsection we assume that capital is firm-specific and can only be augmented with a one-period delay.

\subsection{The Calvo Model with Non Constant Elasticity of Demand}

At time $t$, a final good, $Y_{t}$, is produced by a perfectly competitive firm. The firm does so by combining a continuum of intermediate goods, indexed by $i \in[0,1]$, using the following technology:

$$
\int_{0}^{1} G\left(Y_{i t} / Y_{t}\right) d i=1
$$

Here $G$ is increasing, strictly concave, $G(1)=1$ and $Y_{i t}$ denotes the input of intermediate good $i$. This specification corresponds to the one adopted in Kimball (1995). The standard Dixit-Stiglitz specification corresponds to the special case:

$$
G\left(Y_{i t} / Y_{t}\right)=\left(Y_{i t} / Y_{t}\right)^{(\mu-1) / \mu}, \mu>1
$$

We refer to the general version of $G(\cdot)$ as the Kimball specification.

The final good firm chooses $Y_{t}$ and $Y_{i t}$ to maximize profits, $P_{t} Y_{t}-\int_{0}^{1} P_{i t} Y_{i t} d i$, subject to (1). Here $P_{t}$ and $P_{i t}$ denote the time $t$ price of the final and intermediate good $i$, respectively. The first order conditions to the firm's problem imply

$$
Y_{i t}=Y_{t} G^{\prime-1}\left(\frac{P_{i t} Y_{t}}{\lambda_{t}}\right)
$$


Here $\lambda_{t}$, the time $t$ Lagrange multiplier on constraint (1), is given by:

$$
\lambda_{t}=\frac{P_{t} Y_{t}}{\int G^{\prime}\left(Y_{i t} / Y_{t}\right) \cdot\left(Y_{i t} / Y_{t}\right) d i} .
$$

Throughout, the symbol " denotes the derivative operator and $G^{\prime-1}(\cdot)$ denotes the inverse function of $G^{\prime}(\cdot)$. Our assumptions on $G(\cdot)$ imply that the firm's demand for input $Y_{i t}$ is decreasing in its relative price. ${ }^{5}$

Intermediate good $i \in[0,1]$ is produced by a monopolist who uses the following technology:

$$
Y_{i t}=Z_{t} K_{i t}^{\alpha} H_{i t}^{1-\alpha}
$$

where $0<\alpha<1$. Here, $H_{i t}$ and $K_{i t}$ denote time $t$ labor and capital services used to produce intermediate good $i$, respectively. Intermediate good firms rent capital and labor in economywide, perfectly competitive factor markets. With this specification, individual firms do not view their own capital stock as predetermined within the period. The variable $Z_{t}$ denotes possible stochastic disturbances to technology.

Profits are distributed to the firms' owners at the end of each time period. Let $s_{t}$ denote the representative firm's real marginal cost. Given our assumptions on factor markets, all firms have identical marginal costs. Consequently, we do not index $s_{t}$ by $i$. Marginal cost depends on the parameter $\alpha$ and factor prices that the firm takes as given. The firm's time $t$ profits are $\left[P_{i t} / P_{t}-s_{t}\right] P_{t} Y_{i t}$, where $P_{i t}$ is the price of intermediate good $i$.

Intermediate good firms set prices according to a variant of the mechanism spelled out in Calvo (1983). In each period, a firm faces a constant probability, $1-\theta$, of being able to re-optimize its nominal price. So, on average, a firm re-optimizes its price every $(1-\theta)^{-1}$ periods. The firm's ability to re-optimize its price is independent across firms and time. For now, we leave open the issue of what information set the firm has when it resets its price.

We consider two scenarios for what happens if a firm does not re-optimize its price. In the first scenario, the firm adopts what we call the static indexing scheme, i.e., it updates

\footnotetext{
${ }^{5}$ To obtain this result we use the fact that, given our assumptions on $G$, if $x=G^{\prime-1}(z)$, then $d G^{\prime-1}(z) / d z=1 / G^{\prime \prime}(x)$.
} 
its price according to the rule:

$$
P_{i t}=\bar{\pi} P_{i t-1}
$$

Here $\bar{\pi}$ is the long-run average gross rate of inflation. ${ }^{6}$ In the second scenario, the firm adopts what we call the dynamic indexing scheme, i.e., it sets its price according to ${ }^{7}$

$$
P_{i t}=\pi_{t-1} P_{i t-1}
$$

Let $P_{t}^{*}$ denote the value of $P_{i t}$ set by a firm that can re-optimize its price. In addition, let $Y_{t}^{*}$ denote the time $t$ output of this firm. Our notation does not allow $P_{t}^{*}$ or $Y_{t}^{*}$ to depend on $i$ because all firms who can re-optimize their price at time $t$ choose the same price (see Woodford, 1996 and Yun, 1996). In what follows we focus, for convenience, on specification (4). The firm chooses $P_{t}^{*}$ to maximize

$$
E_{t-\tau} \sum_{l=0}^{\infty}(\beta \theta)^{l} v_{t+l}\left[P_{t}^{*} \bar{\pi}^{l}-s_{t+l} P_{t+l}\right] Y_{t}^{*}
$$

subject to (2). Here, $E_{t-\tau}$ denotes the conditional expectations operator and the firm's $t-\tau$ information set, which includes the realization of all model variables dated $t-\tau$ and earlier. In addition, $v_{t+l}$ is the time-varying portion of the firm's discount factor. The intermediate good firm views $s_{t}, P_{t}, v_{t}$ and $\lambda_{t}$ as exogenous stochastic processes beyond its control.

Let $p_{t}^{*}=P_{t}^{*} / P_{t}$. Log linearizing the first order condition of the firm around the relevant steady state-values we obtain:

$$
\widehat{p}_{t}^{*}=E_{t-\tau} \sum_{l=1}^{\infty}(\beta \theta)^{l} \hat{\pi}_{t+l}+A E_{t-\tau}\left[\hat{s}_{t}+\sum_{l=1}^{\infty}(\beta \theta)^{l}\left(\hat{s}_{t+l}-\hat{s}_{t+l-1}\right)\right]
$$

where

$$
A=\frac{1+G^{\prime \prime}(1) / G^{\prime}(1)}{2+G^{\prime \prime \prime}(1) / G^{\prime \prime}(1)}
$$

Throughout, $\hat{x}_{t}$ denotes the percent deviation of a variable $x_{t}$ from its steady-state value. For future reference it is useful to write $\hat{s}_{t}$ as

$$
\hat{s}_{t}=\hat{W}_{t}-\hat{P}_{t}-\frac{1}{1-\alpha} \hat{Z}_{t}+\frac{\alpha}{1-\alpha} \hat{Y}_{t}-\frac{\alpha}{1-\alpha} \hat{K}_{t}
$$

\footnotetext{
${ }^{6}$ Other authors who make this assumption include Erceg, Henderson and Levin (2000) and Yun (1996).

${ }^{7}$ See Christiano, Eichenbaum and Evans (2004) for a discussion of this form of indexation.
} 
Note that $\hat{s}_{t}$ depends only on economy-wide variables, which an individual firm views as beyond its control.

Several features of (7) are worth emphasizing. First, if inflation is expected to be at its steady state level and real marginal cost is expected to remain constant after time $t$, then the firm sets $\hat{p}_{t}^{*}=A E_{t-\tau} \hat{s}_{t}$. That is, the percent deviation in the firm's relative price is a constant markup of the expected deviation of marginal cost from its steady-state value. Second, suppose the firm expects real marginal costs to be higher in the future than at time $t$. Anticipating those higher future marginal costs, the firm sets $\widehat{p}_{t}^{*}$ higher than $A E_{t-\tau} \hat{s}_{t}$. It does so because it understands that it may not be able to raise its price when higher marginal costs materialize. Third, suppose firms expect future inflation to exceed its steadystate level. To avoid a decline in its relative price, the firm incorporates expected changes in the inflation rate into $\widehat{p}_{t}^{*}$.

The degree to which $\widehat{p}_{t}^{*}$ responds to current and future values of $\hat{s}_{t}$ is increasing in $A$, which in turn depends on the properties of $G(\cdot)$. One way to interpret $A$ is that it governs the degree of pass-through from a rise in marginal cost to prices. For example, according to (7), a highly persistent $1 \%$ increase in time $t$ marginal cost from its steady state value induces the firm to initially raise its relative price by approximately $A$ percent.

A different way to interpret $A$ involves the elasticity of demand for a given intermediate good, $\eta(x)=-G^{\prime}(x) /\left(x G^{\prime \prime}(x)\right)$, where $x=Y_{t}^{*} / Y_{t}$. In the Appendix we show that

$$
A=\frac{1}{\zeta \epsilon+1},
$$

where $\epsilon=(\tilde{P} / \eta(1))(\partial \eta(1) / \partial \tilde{P})$. The variable $\epsilon$ is the percent change in the elasticity of demand due to a one percent change in the relative price of the good, evaluated in steady state. The variable $\zeta$ denotes the firm's steady state markup, $\eta(1) /(\eta(1)-1)-1$. In the standard Dixit Stiglitz case, $\epsilon$ is equal to zero and $A$ is equal to one.

Relations (9) and (7) imply that the larger is $\epsilon$, the lower is $A$ and the less responsive is $\widehat{p}_{t}^{*}$ to current and future values of $\hat{s}_{t}$. To understand these relationships, recall that, other things being equal, a rise in marginal cost induces a firm to increase its price. A higher value of $\epsilon$ means that, for any given rise in its price, the more elastic is the demand curve for the firm's good. So, relative to the case where $\epsilon=0$, the firm will raise its price by less. As we discuss below, this means that inflation will respond by less to movements in marginal cost. 
Zero profits in the final goods sector and our assumptions about the distribution of $\theta$ across firms and time imply

$$
P_{t} Y_{t}=\int_{0}^{1} P_{i t} Y_{i t}=(1-\theta) P_{t}^{*} Y_{t+l} G^{\prime-1}\left(\frac{P_{t}^{*} Y_{t}}{\lambda_{t}}\right)+\theta \bar{\pi} P_{t-1} Y_{t} G^{\prime-1}\left(\frac{\bar{\pi} P_{t-1} Y_{t}}{\lambda_{t}}\right)
$$

Linearizing this relationship around the steady-state values of the variables in (10) yields the standard relationship $\widehat{p}_{t}^{*}=\theta \hat{\pi}_{t} /(1-\theta)$. Combining this equation and (7) we obtain

$$
\hat{\pi}_{t}=\beta E_{t-\tau} \hat{\pi}_{t+1}+\frac{(1-\beta \theta)(1-\theta)}{\theta} A E_{t-\tau} \hat{s}_{t}
$$

When $\tau=0$ and $A=1$ (the Dixit-Stiglitz case), (11) reduces to the standard relationship between inflation and marginal costs studied in the literature. ${ }^{8}$

Iterating forward on (11) yields

$$
\hat{\pi}_{t}=\frac{(1-\beta \theta)(1-\theta)}{\theta} A E_{t-\tau} \sum_{j=0}^{\infty} \beta^{j} \hat{s}_{t+j}
$$

Relation (12) makes clear a central prediction of the model: deviations of inflation from its steady state value depend only on firms' expectations of current and future deviations of real marginal cost from its steady state value. The lower is $A$, i.e., the more sensitive is the elasticity of demand for intermediate goods to price changes, the less responsive is $\hat{\pi}_{t}$ to changes in expected values of $\hat{s}_{t+j}$. Similarly, the higher is $\theta$, the smaller will be the response of $\hat{\pi}_{t}$ to expected changes in marginal cost. So the version of the Calvo model considered in this subsection has two distinct mechanisms that can account for a small response of inflation to movements in marginal cost.

In the case where firms adopt the dynamic indexing rule, (5), the linearized first order condition is

$$
\hat{p}_{t}^{*}=E_{t-\tau} \sum_{l=1}^{\infty}(\beta \theta)^{l} \Delta \hat{\pi}_{t+l}+A E_{t-\tau}\left[\hat{s}_{t}+\sum_{l=1}^{\infty}(\beta \theta)^{l}\left(\hat{s}_{t+l}-\hat{s}_{t+l-1}\right)\right]
$$

\footnotetext{
${ }^{8}$ We derived (11) by linearizing around steady state inflation $\bar{\pi}$. Various authors assume that firms which do not reoptimize prices leave their price unchanged, i.e., $P_{i t}=P_{i t-1}$. The model is then linearized around $\bar{\pi}=1$. Since $\hat{\pi}_{t}$ is defined as the percentage deviation from steady state, (11) does not depend on the assumed value of $\bar{\pi}$.
} 
and (11) takes the form

$$
\Delta \hat{\pi}_{t}=\beta E_{t-\tau} \Delta \hat{\pi}_{t+1}+\frac{(1-\beta \theta)(1-\theta)}{\theta} A E_{t-\tau} \hat{s}_{t}
$$

In addition, (12) is replaced by

$$
\Delta \hat{\pi}_{t}=\frac{(1-\beta \theta)(1-\theta)}{\theta} A E_{t-\tau} \sum_{j=0}^{\infty} \beta^{j} \hat{s}_{t+j} .
$$

Here, $\Delta$ denotes the first difference operator. Notice that with dynamic indexation, it is the first difference of $\hat{\pi}_{t}$ that is a weighted average of expected current and future values of $\hat{s}_{t}$.

\subsection{Firm-specific Capital}

Standard variants of the Calvo model assume that firms rent capital and purchase labor services in perfectly competitive economy-wide markets. Woodford (2003) has proposed a variant of the Calvo model in which capital is firm-specific. In this specification, a firm's capital can only be augmented with a one-period delay using final goods, subject to adjustment costs. These assumptions imply that, unlike the case in which capital is not firm-specific, intermediate good firms do not view marginal costs as being beyond their ability to control. As we show below, this perturbation of the Calvo model allows it to account for the time series behavior of inflation with less inertia in firms' pricing plans, i.e., lower values of $\theta$.

The basic intuition for this claim can be described as follows. With firm-specific capital, a firm's marginal cost depends partly on economy-wide factors such as the real wage rate and the aggregate level of technology. But, because its stock of capital is predetermined, a firm's marginal cost is also an increasing function of its output. Consider a shock that raises the economy-wide component of marginal costs, such as a rise in the real wage rate. Other things equal, a firm that is re-optimizing its price will respond by planning to raise its price. However, this rise in price reduces output, which leads to a countervailing fall in marginal cost. Therefore, the firm will plan to raise its price by less than it would have were capital not predetermined. The presence of adjustment costs implies that the firm will only slowly adjust its stock of capital. Consequently, the dynamic effects stemming from adjustment costs reinforce the effects of predetermined capital on firms' pricing decisions.

To be concrete, we now briefly describe a version of Woodford's (2003) model in which 
final output is produced using the Kimball specification (see (1)). We refer the reader to the appendix for details. The model is identical to the one described in the previous subsection except for the nature of capital. At time $t$, firm $i$ 's capital, $K_{i t}$, is given. The firm can augment its capital by purchasing time $t$ output of the final good sector. But it does so subject to convex capital adjustment costs. Specifically, increasing capital to $K_{i t+1}$ in period $t+1$ requires time $t$ investment, $I_{i t}$, satisfying

$$
I_{i t}=Q\left(\frac{K_{i t+1}}{K_{i t}}\right) K_{i t} .
$$

The function $Q(\cdot)$ satisfies the following properties: $Q(1)=\delta, Q^{\prime}(1)=1$ and $Q^{\prime \prime}(1)=\psi$, where $0<\delta<1$ and $\psi \geq 0$. In non-stochastic steady state, investment is equal to $\delta$ times the steady-state capital stock. So, we can interpret $\delta$ as the steady-state rate of capital depreciation. The parameter $\psi$ controls the degree of adjustment costs. For simplicity, we assume that capital decisions are made subject to the same timing constraints as price decisions. Specifically, we assume $I_{i t}$ is chosen at time $t-\tau$. When $\tau=1$, this assumption coincides with the corresponding assumption in Christiano, Eichenbaum and Evans (2004).

The average marginal cost across firms is $s_{t}=\int_{0}^{1} s_{i t} d i$, where $s_{i t}$ is the relevant measure of marginal cost entering into firm $i$ 's pricing decisions. In the appendix we show that the marginal cost for firm $i$ satisfies

$$
\hat{s}_{i t}=\hat{s}_{t}+\frac{\alpha}{1-\alpha}\left[\hat{Y}_{i t}-\hat{Y}_{t}\right]-\frac{\alpha}{1-\alpha}\left[\hat{K}_{i t}-\hat{K}_{t}\right] .
$$

Here, $\hat{s}_{t}$ is given by (8). Unlike the case in which capital is firm-specific, firm $i$ 's marginal cost is not beyond its control. ${ }^{9}$ Instead, $\hat{s}_{i t}$ is an increasing function of firm $i$ 's output relative to economy wide output and a decreasing function of firm $i$ 's capital stock relative to the economy-wide stock of capital.

With the static indexation scheme, the analog to (11) is

$$
\hat{\pi}_{t}=\beta E_{t-\tau} \hat{\pi}_{t+1}+\frac{(1-\beta \theta)(1-\theta)}{\theta} \cdot A \cdot D \cdot E_{t-\tau} \hat{s}_{t},
$$

where $A$ is defined as in (9) and $D$ is a function of the underlying parameters of the model

\footnotetext{
${ }^{9}$ Without firm specific capital, $\hat{Y}_{i t}=\hat{Y}_{t}$ and $\hat{K}_{i t}=\hat{K}_{t}$ and $\hat{s}_{i t}=\hat{s}_{t}$.
} 
(see the Appendix). For simplicity, we summarize this relationship as

$$
D=d(\beta, \alpha, \delta, \psi, \theta, \zeta, \epsilon)
$$

Under dynamic indexation, the analog to (13) is

$$
\Delta \hat{\pi}_{t}=\beta E_{t-\tau} \Delta \hat{\pi}_{t+1}+\frac{(1-\beta \theta)(1-\theta)}{\theta} \cdot A \cdot D \cdot E_{t-\tau} \hat{s}_{t}
$$

For the parameter values that we consider, $D \leq 1$. So, for any given value of $\theta$, firm-specific capital, like a non-constant elasticity of demand, reduces the response of $\hat{\pi}_{t}$ to movements in $\hat{s}_{t}$. So firm-specific capital gives rise to an additional mechanism that generates a small response of inflation to movements in $\hat{s}_{t}$.

In the appendix we show that when adjustment costs approach infinity, that is, as $\psi$ approaches infinity, then

$$
D \rightarrow \frac{1}{1+\bar{\eta} \alpha A /(1-\alpha)}
$$

Under Dixit-Stiglitz, $A=1$ and $\bar{\eta}=\mu$, in which case $D$ corresponds to the coefficient in the model considered by Sbordone (2002) and Galí, Gertler and López-Salido (2001). The key characteristic of that model is that each firm has a fixed stock of firm-specific capital.

\section{Assessing the Empirical Plausibility of the Model}

In this section we discuss two strategies for estimating and testing our variants of the Calvo model. The first corresponds to the strategy pioneered by Hansen (1982) and Hansen and Singleton (1982) and applied to the Calvo model by Galí and Gertler (1999) and Galí, Gertler and López-Salido (2001). The idea is to exploit the fact that in any model incorporating Calvo pricing, certain restrictions must hold. One can analyze these restrictions, without making assumptions about other aspects of the economy. We test these restrictions using Hansen's (1982) 'J statistic'.

A possible shortcoming of tests based on the $J$ statistic is that they may have low power against specific alternatives. Galí and Gertler (1999) argue that this is the case when the Calvo model is confronted with the possibility that some firms adopt backward-looking 'rule of thumb' rules for setting prices. In the second subsection we incorporate this type of firm 
into our analysis and discuss one strategy to test for their presence. An alternative to the limited information methods that we use is to embed our version of the Calvo pricing model within a fully articulated general equilibrium model. One could then estimate and test the model using maximum likelihood methods. Two interesting examples of this approach include Linde (2002) and Smets and Wouters (2003).

\subsection{Testable Implications of the Calvo Model}

To derive the testable implications of the Calvo model, it is convenient to focus on the model with static indexation and define the random variable

$$
\psi_{t+1}=\hat{\pi}_{t}-\beta \hat{\pi}_{t+1}-\frac{(1-\beta \theta)(1-\theta)}{\theta} \cdot A \cdot D \cdot \hat{s}_{t}
$$

Since $\hat{\pi}_{t}$ is in agents' time $t-\tau$ information set, (16) can be written as:

$$
E_{t-\tau} \psi_{t+1}(\sigma)=0
$$

where $\sigma$ denotes the structural parameters of the model. It follows that

$$
E \psi_{t+1}(\sigma) X_{t-\tau}=0
$$

for any $k$ dimensional vector $X_{t-\tau}$ in agents' time $t-\tau$ information set. We exploit (19) to estimate the true value of $\sigma, \sigma_{0}$, and test the over-identifying restrictions of the model using Hansen's (1982) Generalized Method of Moments procedure. ${ }^{10}$

Our estimate of $\sigma$ is

$$
\hat{\sigma}=\arg \min _{\sigma} J_{T}(\sigma)
$$

where

$$
J_{T}(\sigma)=g_{T}(\sigma)^{\prime} W_{T} g_{T}(\sigma)
$$

and

$$
g_{T}(\sigma)=\left(\frac{1}{T}\right) \sum_{t=1}^{T}\left[\psi_{t+1}(\sigma) X_{t-\tau}\right] .
$$

\footnotetext{
${ }^{10}$ We require that $\left\{\hat{\pi}_{t}, \hat{s}_{t}, X_{t}\right\}$ is a stationary and ergodic process.
} 
Here, $T$ denotes the size of our sample and $W_{T}$ is a symmetric positive definite matrix that can depend on sample information. The choice of $W_{T}$ that minimizes the asymptotic covariance matrix of $\hat{\sigma}$ is a consistent estimate of the spectral density matrix of $\left\{\psi_{t+1}\left(\sigma_{0}\right) X_{t-\tau}\right\}$ at frequency zero. Our theory implies that $\psi_{t+1}(\sigma) X_{t-\tau}$ has a moving average representation of order $\tau$. So we choose $W_{T}^{-1}$ to be a consistent estimate of

$$
\sum_{k=-\tau}^{\tau} E\left[\psi_{t+1+k}(\sigma) X_{t+k-\tau}\right]\left[\psi_{t+1+k}(\sigma) X_{t+k-\tau}\right]^{\prime} .
$$

The minimized value of the GMM criterion function, $J_{T}$, is asymptotically distributed as a chi-squared random variable with degrees of freedom equal to the difference between the number of unconditional moment restrictions imposed $(k)$ and the number of parameters being estimated. ${ }^{11}$

One does not have to impose the restriction that $\psi_{t+1}(\sigma) X_{t-\tau}$ has an $M A(\tau)$ representation when constructing an estimate of $W_{T}^{-1}$. Specifically, one could allow for higher-order serial correlation in the error term than the theory implies. However, as we describe below, whether one does so or not has an important impact, in practice, on inference.

It is evident from (18) and (20) - (22) that $\theta, A$ and $D$ are not separately identified. All that can be identified given the assumptions made so far is the reduced form parameter

$$
c=A \cdot D \cdot \frac{(1-\beta \theta)(1-\theta)}{\theta} .
$$

However, given any estimate of $c, \hat{c}$, and assumed values for $A$ and $D$, one can deduce the implied value of $\theta$. When capital is not firm-specific, we have $D=1$, and $\theta$ can be derived from the relation

$$
A=\frac{\theta \hat{c}}{(1-\beta \theta)(1-\theta)} .
$$

Here $\mathrm{A}$ is function of $\zeta$ and $\epsilon$. When capital is firm-specific, one can deduce $\theta$ using (17) and

$$
A=\frac{\theta \hat{c}}{D(1-\beta \theta)(1-\theta)} .
$$

\footnotetext{
${ }^{11}$ According to relation (12), $\hat{\pi}_{t}$ is predetermined at time $t-\tau$. If we were only interested in assessing the hypothesis that inflation is predetermined at time $t-\tau$, we could test whether any variable dated between time $t-\tau$ and $t$ has explanatory power for time $t$ inflation.
} 
The previous discussion implies that, given priors about a key subset of the model's structural parameters and the nature of capital markets, we can deduce the degree of inertia in price optimization $(\theta)$ required to render the extended Calvo model consistent with the aggregate time series data.

\subsection{Testing the Calvo Model Against a Specific Alternative}

Galí and Gertler (1999) have argued it is necessary to allow for backward looking 'rule of thumb' firms to render the Calvo model consistent with the data. Here we show how to incorporate the presence of Galí - Gertler-type 'rule of thumb' firms into our analysis. ${ }^{12}$ As in our basic model, we consider two cases corresponding to whether optimizing firms update their prices using static or dynamic optimization rules. For simplicity, we derive the model under the assumption that capital is not firm-specific and $A=1$.

\section{Optimizing Firms With Static Indexation}

Following Galí and Gertler (1999), we assume that there are two types of firms in the economy. A fraction $(1-\omega)$ of intermediate good firms are optimizing Calvo type firms. That is, they face a constant probability, $1-\theta$, of being able to re-optimize their nominal price. As above, when they re-optimize, they solve problem (6) subject to (2). When they do not re-optimize, they adopt the static optimization scheme, (4). A fraction $\omega$ of intermediate good firms adopt the rule of thumb for setting prices discussed in Galí and Gertler (1999). With probability $\theta$, rule of thumb firm $i$ sets its price according to ${ }^{13}$

$$
P_{i t}=\bar{\pi} P_{i t-1}
$$

With probability $(1-\theta)$, this firm sets its price according to

$$
P_{t}^{\prime}=\pi_{t-1} \bar{P}_{t-1}
$$

\footnotetext{
${ }^{12}$ An important motivation for introducing 'rule- of-thumb' firms is the observed inertia in inflation. See Linde (2001) for a discussion of the difficulties that standard dynamic general equilibrium models have in accounting for the backward-looking component of inflation.

${ }^{13}$ This rule is precisely the same as the one considered by Gali and Gertler (1999) except that they assume $\bar{\pi}=1$. As explained above, this assumption has no impact on the estimation equations used in the analysis.
} 
Here

$$
\bar{P}_{t}=(1-\omega) P_{t}^{*}+\omega P_{t}^{\prime},
$$

and $P_{t}^{*}$ denotes the price set by firms that can re-optimize their price at time $t$. The aggregate price level is given by

$$
P_{t}=\left[(1-\theta)\left(\bar{P}_{t}\right)^{\frac{1}{1-\mu}}+\theta\left(\bar{\pi} P_{t-1}\right)^{\frac{1}{1-\mu}}\right]^{1-\mu} .
$$

Log linearizing (27) - (30) and combining the resulting expressions with (7), one can show that the analog to (11) is given by:

$$
\hat{\pi}_{t}=\frac{\beta \theta}{\phi} E_{t-\tau} \hat{\pi}_{t+1}+\frac{\omega}{\phi} \hat{\pi}_{t-1}+\frac{(1-\omega)(1-\beta \theta)(1-\theta)}{\phi} E_{t-\tau} \hat{s}_{t}
$$

where $\phi=\theta+\omega[1-\theta(1-\beta)]$. As long as $\omega>0$, rule-of-thumb firms generate additional persistence in inflation in the sense that $\pi_{t-1}$ appears in (31). When $\omega=0,(31)$ collapses to the analog expression for $\hat{\pi}_{t}$ in the standard Calvo model with static indexing.

\section{Optimizing Firms With Dynamic Indexation}

We now modify the version of the Galí-Gertler model discussed above on exactly one dimension: we assume that optimizing firms adopt the dynamic optimization scheme (5) instead of the static scheme (4). With this modification, the aggregate price level is given by:

$$
P_{t}=\left[(1-\theta)\left(\bar{P}_{t}\right)^{\frac{1}{1-\mu}}+\theta\left((1-\omega) \pi_{t-1} P_{t-1}+\omega \bar{\pi} P_{t-1}\right)^{\frac{1}{1-\mu}}\right]^{1-\mu} .
$$

Replacing (30) with (32) in the derivation with static indexation, one can show that the analog to (11) is given by

$$
\begin{gathered}
\Delta \hat{\pi}_{t}=\frac{\beta \theta}{\phi^{\prime}} \Delta \hat{\pi}_{t+1}+\frac{\omega \theta}{\phi^{\prime}}(1-\omega) \Delta \hat{\pi}_{t-1} \\
+\frac{\omega \theta}{\phi^{\prime}}(1-\omega)(1-\beta \theta) \hat{\pi}_{t-1}+\frac{(1-\omega)(1-\beta \theta)(1-\theta)}{\phi^{\prime}} E_{t-\tau} \hat{s}_{t},
\end{gathered}
$$

where $\phi^{\prime}=\theta(1-\omega)+\omega$. Notice that rule of thumb firms imply that both $\Delta \hat{\pi}_{t-1}$ and $\hat{\pi}_{t-1}$ appear in the equilibrium relationship determining $\Delta \hat{\pi}_{t}$. When $\omega=0,(33)$ collapses to the analog expression for $\hat{\pi}_{t}$ in the standard Calvo model under the dynamic indexing scheme.

\section{Estimation and Testing}


We estimate the parameters of the model described in this section using the methodology and instruments described in section 4.1. The key modification is that, under static indexation, equation (31) replaces (11). Under dynamic indexation, (33) replaces (13). To test the model against the general alternative that the model is misspecified, we use Hansen's $J_{T}$ statistic. More interestingly, in the present context, we can test the standard Calvo model against the specific alternative that there exist rule-of-thumb firms by assessing whether the parameter $\omega$ is significantly different from zero.

\section{Data}

Our benchmark sample period is 1959:1 - 2001:4. However, numerous observers have argued that there was an important change in the nature of monetary policy with the advent of the Volker disinflation in the early 1980s. It is also often argued that the Fed's operating procedures were different in the early 1980s than in the post-1982 period. Accordingly, we re-estimated the model over the two distinct subsamples used in Galí, Lopez-Salido and Vallés (2003): 1959:1-1979:2 and 1982:3- 2001:4. We report results for two measures of inflation: the GDP deflator and the price deflator for personal consumption expenditures. ${ }^{14}$ We measure $\hat{\pi}_{t}$ as the difference between actual time $t$ inflation and the sample average of inflation.

In the case where capital is not firm-specific, real marginal costs are equal to the real product wage divided by the marginal product of labor. Production function (3) implies that real marginal cost is proportional to labor's share in national income, $W_{t} H_{t} /\left(P_{t} Y_{t}\right)$, where $W_{t}$ is the nominal wage. In practice, we measure $W_{t} H_{t}$ as nominal labor compensation in the non-farm business sector. Our measure of $P_{t} Y_{t}$ is nominal output of the non-farm business sector. The variable $\hat{s}_{t}$ is measured as the difference between the log of the time $t$ value of our measure of labor's share in national income and its sample average. This is a standard measure of $\hat{s}_{t}$ which has been used by Galí and Gertler (1999), Galí et. al. (2001) and Sbordone (2002). As it turns out, this is the correct measure of $\hat{s}_{t}$ even when capital is firm-specific (see the Appendix).

Rotemberg and Woodford (1999) discuss possible corrections to this measure that are

\footnotetext{
${ }^{14}$ All data sources are listed in the Appendix. We also considered the price deflator for the non-farm business sector and the consumer price index (CPI) and found that our key results are insensitive to these alternative measures.
} 
appropriate for different assumptions about technology. These corrections include those that take into account a non-constant elasticity of factor substitution between capital and labor and the presence of overhead costs and labor adjustment costs. We redid our analysis for these alternative measures of marginal costs and found that they do not affect the qualitative nature of our results. ${ }^{15}$

Consider next the instrument vector $X_{t-\tau}$. Let $Z_{t}$ denote the four-dimensional vector consisting of the time $t$ value of real marginal cost, quadratically detrended real GDP, inflation, and the growth rate of nominal wages in the non farm business sector. Our specification of $X_{t-\tau}$ is given by ${ }^{16}$

$$
X_{t-\tau}=\left\{1, Z_{t-\tau}, \psi_{t-\tau}\right\}^{\prime}
$$

We include lagged values of the Euler error, $\psi_{t}$, because we found that doing so increased the power of our statistical tests (see below).

\section{Empirical Results}

In this section we present our empirical results. To facilitate comparisons with the literature, we report point estimates of $\theta$ corresponding to the identifying assumption that capital is mobile and $G(\cdot)$ in (1) is of the Dixit-Stiglitz form. The first subsection reports results for the case in which there are no delays in implementing new optimal price decisions $(\tau=0)$. When $A=1$ and capital is firm-specific, this case corresponds to the standard Calvo model. In the second subsection, we discuss the impact of allowing for a delay in implementing new optimal price decisions. In the third subsection, we report results for the Galí and Gertler (1999) 'rule of thumb' version of the model.

\footnotetext{
${ }^{15}$ See also Gagnon and Khan (2004) who study versions of the Calvo model under different assumptions about marginal cost.

${ }^{16}$ Gali and Gertler (1999) use an instrument list consisting of a constant and lagged values of $Z_{t}$, where the latter is augmented to include an index of commodity prices and the spread between the annual interest rate on the ten year Treasury Bond and three month bill. We redid our basic analysis, setting $X_{t}$ to $\left\{1, Z_{t-j}, j=0,1,2,3\right\}^{\prime}$ and $\left\{1, Z_{t-j}, j=1,2,3,4\right\}$. Gali et..al. (2001) adopt the same specification as we do but set $X_{t}=\left\{1, Z_{t-j}, j=1,2,3,4\right\}$. It turns out that the point estimates are similar across different specifications of $X_{t}$, including the one used in this paper. However, using a larger set of instruments leads to misleading inference about the plausibility of the overidentifying restrictions implied by the model. Specifically, often we cannot reject the model with a larger set of instruments on the basis of the $J_{T}$ statistic, but we can do so with the smaller set of instruments.
} 


\subsection{The Standard Calvo Model}

We begin by analyzing results for the standard Calvo model $(\tau=0)$ in the case where firms adopt the static indexing scheme. The top panel of Table 1 summarizes results obtained using the full sample. We report our estimate of the parameter $\theta$ (standard error in parenthesis) and the $J_{T}$ statistic (p-value in square brackets). The label $L$ refers to the maximal degree of serial correlation that we allow for when estimating the weighting matrix $W_{T}$. Initially we consider two values for $L$ : (i) $L=0$, which corresponds to the degree of serial correlation in $\psi_{t+1}$ implied by this version of the model, and (ii) $L=12$, the value used by Galí and Gertler (1999). Both values of $L$ are admissible. But, by setting $L$ to zero we are imposing all of the restrictions implied by the model. This restriction may lead to greater efficiency of our estimator and more power in our test of the model's over-identifying restrictions.

Recall that Table 1 presents our estimates of the model's parameters under the assumption that $A$ and $D$ equal one. Notice that $\theta$ is estimated with relatively small standard errors. In addition, the point estimate itself is reasonably robust across the different inflation measures and the two values of $L$, ranging from a low of 0.87 to a high of 0.91 . This implies that on average, firms wait between 7.5 and 11 quarters before re-optimizing their prices. This result is consistent with findings in Smets and Wouters (2003) who find, using maximum likelihood methods, that high degrees of price inertia are required to render a standard Calvo model consistent with the data. This result is also consistent with findings in Galí and Gertler (1999).

We hesitate to attribute much importance to these point estimates. When $L=12$, the model cannot be rejected at the $1 \%$ significance level, although it can be rejected at the $5 \%$ significance level. However, when we set $L=0$, the model is strongly rejected for both inflation measures. Evidently, imposing all of the relevant restrictions implied by the model on the weighting matrix has an important impact on inference.

The middle and bottom panels of Table 1 report our sub-sample results. Note that when $L=12$, there is virtually no evidence against the model for either measure of inflation, regardless of which subsample we consider. As with the full sample results, inference is significantly affected by setting $L=0$. In the first sample period, the model is now rejected at the $5 \%$ significance level for both measures of inflation. In the second subsample, the model is decisively rejected using data from the second subsample when we measure inflation using the GDP deflator. There is considerably less evidence against the model in this case when 
we use the PCE deflator-based measure of inflation. Comparing the point estimates in the three panels, we see that inference about $\theta$ is reasonably robust to allowing for a split in the sample. As above, we are hesitant to attach much importance to this result in light of the overall statistical evidence against the standard Calvo model.

Table 2 reports results when we allow for dynamic indexation. The key result to note is that this version of the model is also rejected when we set $L=0$. Viewed overall, we conclude that there is strong statistical evidence against the standard Calvo model.

\subsection{Alternative Timing Assumptions}

Table 3 reports the results of estimating the model when $\tau=1$ and we assume that firms adopt the static indexation scheme, (4). In the previous subsection we showed that imposing the degree of serial correlation in $\psi_{t+1}$ implied by the model on the estimator of the weighting matrix, $W_{T}$, improves the power of our statistical tests. So, for the remainder of the analysis, we report results only for the case where these restrictions are imposed. In the case of $\tau=1$, this means setting $L=1$. The instruments used are

$$
X_{t-1}=\left\{1, Z_{t-1}, \psi_{t-1}\right\}^{\prime}
$$

Two key results from Table 3 are worth reporting. First, regardless of which sample period we consider or which measure of inflation we use, there is virtually no statistical evidence against the model. Second, $\theta$ is estimated with reasonable precision with the point estimates ranging from a low of 0.83 to a high of 0.91 . This corresponds to firms changing prices on average from between 6 quarters and 11 quarters, which seems implausible high.

Table 4 reports the results of estimating the model when $\tau=1$ and we assume that firms adopt the dynamic indexation scheme, (5). As with the static indexing scheme, there is virtually no statistical evidence against the model. Moreover, the point estimates of the parameters $\theta$ are quite similar, now ranging from a low 0.83 to a high of 0.89 .

We conclude that allowing for a one period lag $(\tau=1)$ in the implementation of new pricing plans is sufficient to overturn our statistical evidence against the standard Calvo model. But it is not sufficient to generate economically plausible parameter estimates of the degree of inertia in price re-optimization. Note, however, that this conclusion is conditional on the assumption that intermediate goods are combined via a Dixit-Stiglitz technology to 
produce final goods $(A=1)$ and that capital is not firm-specific $(D=1)$. Before exploring the quantitative trade-off between the parameter $A$, the nature of capital markets, and the degree of price stickiness, we investigate the claim that the standard Calvo model must be modified to allow for the presence of rule-of-thumb firms.

\section{3. 'Rule of Thumb' Firms}

We now report the results of estimating the Calvo model, modified to allow for backwardlooking 'rule of thumb' firms. We begin by confirming Galí and Gertler's result that there is evidence of backward looking firms under the static indexation scheme. We then show that this evidence disappears under the dynamic indexing scheme. Throughout we assume, as do Galí and Gertler, that $\tau=1$.

Table 5 summarizes our results for the static indexation case. Four key findings are worth noting. First, using the full sample, we estimate that roughly $50 \%$ of firms behave in a rule-of-thumb manner, with the exact percent depending on how we measure inflation. In both cases, we can reject, at conventional significance levels, the null hypothesis that there are no rule-of-thumb firms $(\omega=0)$. Second, there is virtually no evidence against the over-identifying restrictions imposed by the model. Third, the point estimates of $\theta$ still seem implausibly large. Fourth, there is little evidence of rule-of-thumb firms once we allow for a split in the sample if we measure inflation using the GDP deflator. But there is still evidence that $\omega$ is greater than zero when we measure inflation using the PCE deflator, at least in the second subsample.

Viewed overall, the results in Table 5 are consistent with Galí and Gertler's conclusion that the standard Calvo model with static indexation is rejected when we test it against a specific alternative, namely, the presence of some rule-of-thumb firms. Table 6 reports our results for the case of dynamic indexation. Three key findings emerge. First, our point estimates of $\omega$ are substantially smaller than those emerging under the assumption that optimizing firms adopt the static indexation scheme. Indeed, for the full sample, our point estimates are roughly equal to zero. Second, our point estimates of $\theta$ are similar to those obtained when we estimated the model under the constraint that $\omega$ is equal to zero (see Table 4). Perhaps most importantly, there is virtually no evidence of rule-of-thumb firms. Regardless of which sample we consider or which measure of inflation we use, we cannot reject the null hypothesis that $\omega=0$. We conclude that the evidence for rule-of-thumb firms 
disappears once we allow for dynamic indexation.

\section{Interpreting the Estimated Calvo Model}

In Section 5 we argued that there is little evidence against the version of the Calvo model with a one-period implementation lag, optimizing firms use the dynamic indexation scheme, and there are no rule-of-thumb firms. However, the estimated degree of inertia in price re-optimization implied by the model seems implausibly large. Taken at face value, these findings indicate that the Calvo model can be rescued statistically, but not in any interesting economic sense. However, this conclusion follows only under the maintained assumptions that firms face a constant elasticity of demand $(A=1)$ and that capital is not firm-specific $(D=1)$. In this section we explore the sensitivity of inference about $\theta$ to these assumptions. Specifically, we analyze the quantitative trade-off between $\theta$, the nature of capital markets, and the elasticity of demand for intermediate goods with respect to relative prices, $\epsilon$.

Recall that the relationship between the reduced parameter $c$ and the underlying parameters of the model is given by expressions (17) and (24) - (26). Suppose we have an estimate of $c$ and values for $(\beta, \alpha, \delta, \zeta)$. In the case where capital is not firm-specific, these equations reduce to one equation in two unknowns, $\theta$ and $\epsilon$. When capital is firm-specific, we have two equations in three unknowns $\theta, \psi$ and $\epsilon$. In general, different values of $\psi$ and $\epsilon$ imply different values of $\theta$ that are consistent with a given estimate of $c$.

To explore the nature of these trade-offs, we proceed as follows. We set the share of capital in the production function, $\alpha$, to $1 / 3$, the quarterly depreciation rate of capital, $\delta$, to 0.025 , the markup, $\zeta$, equal to $10 \%$ and the discount rate, $\beta$, to 0.99 . We consider three values for $\epsilon$ : 0, 10 and 33. Recall that $\epsilon$ equal to zero corresponds to the Dixit - Stiglitz case. The case of $\varepsilon=10$ is consistent with results in Bergin and Feenstra (2000). The case of $\epsilon$ equal to 33 is the benchmark value considered in Kimball (1995).

When firm capital is not firm-specific, $D=1$ and the parameter $\psi$ does not appear in the model. When capital is firm-specific we consider three values of $\psi$. First, we assume that $\psi=0$. This assumption allows us to disentangle the impact of pre-determined firmspecific capital per se from the effect of capital adjustment costs. Second, we set $\psi$ equal to three, the value emphasized in Woodford (2003). The parameter $\psi$ can be interpreted as the elasticity of the investment-to-capital ratio with respect to Tobin's $q$, evaluated in steady state. As shown in the appendix, for our model, this elasticity is given by $1 /(\delta \psi)$. 
With $\delta=0.025$ and $\psi=3$, this elasticity is equal to 13.3 , a value that is large relative to those reported in the literature (see Christiano and Fisher 1998). In this sense, $\psi=3$ is a conservative choice; we would have to assume larger adjustment costs to obtain elasticities closer to those in the literature. Finally, in results not reported here, we also considered the case of $\psi$ equal to infinity. Here the elasticity of the investment-to-capital ratio with respect to Tobin's $q$ is equal to zero. This case corresponds to Sbordone's (2002) assumption that capital is firm-specific and cannot be augmented over time. As it turns out, raising $\psi$ from three to infinity to $\psi=\infty$ has very little impact on our findings.

Table 7 reports results based on estimates of $c$ implied by Table $4(\tau=1$, dynamic indexation and no rule-of-thumb firms). The values in square brackets represent $95 \%$ confidence intervals. ${ }^{17}$ Since our findings are similar for the two inflation measures, we focus on the GDP deflator case. Three key results emerge from Table 7. First, as anticipated, $\theta$ is a declining function of $\epsilon$. For example, when capital is not firm-specific, the point estimate of $\theta$ falls from 0.88 to 0.76 as $\epsilon$ rises from the benchmark value of 0 to 33 . This fall corresponds to a decline in the average frequency with which firms re-optimize prices from roughly two years to one year. Second, for any given value of $\epsilon, \theta$ decreases if we assume that capital is firm-specific. For $\psi=3$, our point estimate of $\theta$ is less than 0.75 (a re-optimization rate of at least one year) regardless of which value of $\epsilon$ we work with. By comparing the case of $\psi=0$ and $\psi=3$, we see that the fall in $\theta$ is partly attributable to the effect of predetermined capital per se and partly to the effect of capital adjustment costs. As mentioned above, assuming larger adjustment costs has very little impact on inference regarding $\theta$. Third, conditional on the presence of firm-specific capital, there is only marginal evidence against the null hypothesis that firms re-optimize prices every half-year. ${ }^{18}$

Table 8 reports the analog statistics calculated for values of $c$ estimated allowing for a break in the sample period. Notice that the qualitative results from Table 7 are very robust to this change: allowing for a non-constant elasticity of demand or firm-specific capital leads to lower values of $\theta$. Perhaps more importantly, the reported values of $\theta$ are lower than those reported in either Table 4 or Table 7 . It is useful to focus on the case in which capital is

${ }^{17}$ These intervals were calculated as follows. Using the information from Table 4, we construct a $95 \%$ confidence interval for $c$. Then, for the different specifications of our model, we compute the values of $\theta$ that correspond to the lower and upper values of the confidence intervals for $c$. Using these values of $\theta$, we computed the corresponding lower and upper values of $1 /(1-\theta)$.

${ }^{18}$ The confidence intervals for the statistic $1 /(1-\theta)$ are asymmetric. Because of the nonlinear nature of this function, the right hand tail of the reported confidence intervals are very large. 
firm-specific. With $\psi=3$, our point estimate of $\theta$ is substantially lower than 0.75 , varying from a low of 0.56 to a high of 0.67 , depending on the value of $\epsilon$ we assume. So the average amount of time between price re-optimization ranges from 2.3 and roughly 3 quarters. In no case can we reject the hypothesis that firms re-optimize prices on average every 2 quarters.

We conclude by discussing the relationship between the properties of our estimated model and recent findings in the literature regarding the degree of price stickiness based on microeconomic data. Using disaggregated CPI data from the greater New York metropolitan area over the period 1988 to 1997, Golosov and Lucas (2003) report that roughly $21.9 \%$ of prices of items in the CPI basket remain unchanged each month. Using data from New York, Chicago and Los Angeles over the sample period 1988-2003, Klenow and Krystov (2003) report that $24.8 \%$ of prices of items in the CPI basket remain unchanged every month. ${ }^{19}$

Comparing our variants of the Calvo model with these findings is delicate. At one level, the models in this paper imply that prices change too frequently relative to the micro data. This is because with price indexation, all prices are changing all the time. An even more subtle difficulty is that just because firms are changing prices does not mean that they have re-optimized those prices: a subset of the price changes being recorded could reflect various forms of time dependent price updating rules. So, in principle, our model could be consistent with findings that prices change all the time.

Despite these difficulties, we think it is still useful to compare the average frequency with which firms re-optimize prices in the estimated version of our model with the findings in Golosov and Lucas and Klenow and Krystov. Golosov and Lucas' estimates imply that firms change prices once every 1.9 quarters, while Klenow and Krystov's estimates imply that firms change prices roughly every $1.7-1.8$ quarters. Table 8 indicates that, based on the GDP deflator, in the version of the model with firm specific capital and $\psi=3$, we can never reject the hypothesis that firms re-optimize prices, on average, every 1.8 quarters. With the PCE deflator, we can never reject the hypothesis that firms re-optimize prices, on average, every 1.9 quarters. In this sense, our model seems consistent with the findings in Golosov and Lucas and Klenow and Krystov.

We are not claiming that our variants of the Calvo model are literally 'true'. There are some obvious aspects of these models that are counterfactual, such as the implication

\footnotetext{
${ }^{19}$ In both cases, these fractions are based on data excluding sales. Interstingly, Klenow and Krystov also report that roughly $90 \%$ of the variance in monthly inflation stems solely from fluctuations in the average size of price changes. This last finding is inconsistent with a large class of state dependent pricing models.
} 
that some firms never re-optimize prices. Nevertheless, the degree of inertia in price reoptimization implied by the estimated version of our model does not seem implausible relative to the findings in Golosov and Lucas and Klenow and Krystov.

\section{Conclusion}

This paper assesses the empirical performance of the Calvo model of sticky goods prices. We argue that a version of the model in which there is a one-quarter delay in the implementation of new prices and dynamic indexation renders the model consistent with the aggregate data in a statistical sense. A separate question is whether the estimated model implies plausible inertia in price setting behavior by firms. On the face of it, the answer to this question is no: our benchmark model implies that firms re-optimize prices roughly once every seven quarters.

However, this conclusion is not warranted once we abandon two special auxiliary assumptions associated with standard expositions of the Calvo model: (i) monopolistically competitive firms face a constant elasticity of demand and (ii) capital is not firm-specific and can be instantaneously reallocated after a shock. Once we abandon these assumptions, the estimated model implies a degree of inertia in price re-optimization that is much more plausible. Specifically, it is consistent with the hypothesis that firms re-optimize prices at least once every two quarters. This result holds even though the model is observationally equivalent to the original model in terms of its implications for the time series data on inflation. 


\section{References}

[1] Bergin, Paul and Robert Feenstra, "Staggered Price Setting, Translog Preferences, and Endogenous Persistence," Journal of Monetary Economics, 2000, v. 45, pp. 657-680.

[2] Bils, Mark and Peter Klenow, "Some Evidence on the Importance of Sticky Prices," December 2003, forthcoming in the Journal of Political Economy.

[3] Burstein, Ariel, "Inflation and Output Dynamics with State Dependent Pricing Decisions," 2002, manuscript, University of Michigan.

[4] Calvo, Guillermo, "Staggered Prices in a Utility-Maximizing Framework," Journal of Monetary Economics, 1983, 12(3), pp. 383-98.

[5] Christiano, Lawrence, "Notes on Firm-specific Capital," manuscript, 2004.

[6] Christiano, Lawrence, Eichenbaum, Martin and Charles Evans, "Nominal Rigidities and the Dynamic Effects of a Shock to Monetary Policy," 2004, forthcoming, Journal of Political Economy.

[7] Christiano, Lawrence and Jonas Fisher, 1998, "Stock Market and Investment Good Prices: Implications for Macroeconomics," Chicago Fed working paper 98-6.

[8] Dotsey, Michael, King, Robert, G. and Alexander L. Wolman, "State-Dependent Pricing and the General Equilibrium Dynamics of Money and Output," Quarterly Journal of Economics, 1999, 114(2), pp. 655-90.

[9] Erceg, Christopher, J., Henderson, Dale, W. and Andrew T. Levin, "Optimal Monetary Policy with Staggered Wage and Price Contracts," Journal of Monetary Economics, 2000, 46(2), pp. 281-313.

[10] Gagnon, Edith and Hashmat Khan, "New Phillips Curve with Alternative Marginal Cost Measures for Canada, the United States, and the Euro Area," Forthcoming European Economic Review, 2004.

[11] Galí, Jordi, and Mark Gertler, "Inflation Dynamics: A Structural Econometric Analysis," Journal of Monetary Economics, 1999, 44, pp. 195-222.

[12] Galí, Jordi, Mark Gertler and David Lopez-Salido, "European Inflation Dynamics," European Economic Review, 2001, pp. 1237-1270.

[13] Galí, Jordi, David Lopez-Salido and Javier Valles, "Technology shocks and Monetary Policy: Assessing the Fed's Performance," Journal of Monetary Economics, 2003, 50(4), pp. 723-743.

[14] Golosov, M. and R.E. Lucas, Jr. "Menu Costs and Phillips Curves," (2003), manuscript, University of Chicago.

[15] Hansen, Lars P. "Large Sample Properties of Generalized Method of Moments Estimators," Econometrica, 1982, Vol. 50, pp. 1029-1054. 
[16] Hansen, Lars P. and Kenneth J. Singleton, "Generalized Instrumental Variables Estimation of Nonlinear Rational Expectations Models," Econometrica, 1982, Vol. 50, $1269-1286$.

[17] Kimball, Miles, "The Quantitative Analytics of the Basic Neomonetarist Model," Journal of Money, Credit, and Banking, 1995, 27(4), Part 2, pp. 1241-1277.

[18] Klenow, P. and O. Krystov, "State-Dependent or Time-Dependent Pricing: Does it Matter for Recent US Inflation," Stanford University, manuscript, September 2003.

[19] Linde, Jesper, "The Empirical Relevance of Simple Forward- and Backward-Looking Models: A View From a Dynamic General Equilibrium Model," 2001, Sveriges Riksbank Working Paper No. 130.

[20] Linde, Jesper, "Estimating New-Keynesian Phillips Curves: A Full Information Maximum Likelihood Approach," 2002, Sveriges Riksbank Working Paper No. 129.

[21] Rotemberg, Julio J. and Michael Woodford, "An Optimization-Based Econometric Framework for the Evaluation of Monetary Policy," 1997, National Bureau of Economic Research Macroeconomics Annual.

[22] Rotemberg, Julio J. and Michael Woodford, "The Cyclical Behavior of Prices and Costs," Handbook of Macroeconomics, Vol. 1A, eds. Michael Woodford and John Taylor, New York: Elsevier Science, North-Holland, 1999.

[23] Sbordone, Argia, "Prices and Unit Labor Costs: A New Test of Price Stickiness," Journal of Monetary Economics, 2002, 49(2), pp. 265-292.

[24] Smets, Frank and Raf Wouters, "An Estimated Dynamic Stochastic General Equilibrium Model of the Euro Area," Journal of the European Economic Association, 2003, 1(5), pp. 1123-75.

[25] Taylor, John "Aggregate Dynamics and Staggered Contracts," Journal of Political Economy, 1980, Vol. 88, pp. 1-23.

[26] Woodford, Michael, "Control of the Public Debt: A Requirement for Price Stability," 1996, NBER Working Paper 5684.

[27] Woodford, Michael, Interest and Prices: Foundations of a Theory of Monetary Policy, 2003, Princeton University Press: Princeton, NJ.

[28] Woodford, Michael, "Notes on Solving Model with Firm-specific capital," manuscript, 2004.

[29] Yun, Tack, "Nominal Price Rigidity, Money Supply Endogeneity, and Business Cycles," Journal of Monetary Economics, 1996, 37(2), pp. 345 - 370.

[30] Zbaracki, Mark J., Mark Ritson, Daniel Levy, Shantanu Dutta, and Mark Bergen, "The Managerial and Customer Costs of Price Adjustment: Direct Evidence from Industrial Markets," manuscript, 2000, Wharton School, University of Pennsylvania. 


\section{Appendix}

In this appendix we describe the following: (i) data sources, (ii) how to interpret the parameter $A$, (iii) the model without rental markets for capital and $D$, and (iv) how to assess the magnitude of the adjustment cost parameter, $\psi$.

Data

Our data are from the Haver Analytics database. For each data series below, we provide a brief description and, in parenthesis, the Haver codes for the series used.

- Price measures: GDP deflator is the ratio of nominal GDP (GDP) and real chainweighted GDP (GDPH); personal consumption expenditures deflator (JCBM2).

- Real marginal costs: Share of labor income in nominal output for the non-farm business sector, which is proportional to the Bureau of Labor Statistics measure of nominal unit labor costs divided by the non-farm business deflator (LXNFU/LXNFI).

- Adjusted real marginal costs: Per capita hours - hours non-farm business sector (LXNFH) divided by over-16 population (LN16N); Capital-output ratio - annual private fixed capital (EPQ) interpolated with quarterly private fixed investment $(\mathrm{FH})$ divided by GDP (GDPH), all variables in chained 1996 dollars.

- Instruments: Quadratically detrended real GDP is the residual of a linear regression of real GDP (GDPH) on a constant, $t$ and $t^{2}$; inflation is the first difference of the log of the price measures; growth rate of nominal wages is the first difference of the log of nominal compensation in the non-farm business sector (LXNFC).

\section{Interpreting $A$}

Recall that the elasticity of demand for a given intermediate good is

$$
\eta(x)=-\frac{G^{\prime}(x)}{x G^{\prime \prime}(x)}
$$

where

$$
x=\frac{Y^{*}}{Y} .
$$

The coefficient $A$ can be written

$$
A=\frac{1-1 / \bar{\eta}}{2+G^{\prime \prime \prime}(1) / G^{\prime \prime}(1)}
$$

where $\bar{\eta}=-G^{\prime}(1) / G^{\prime \prime}(1)$ is the steady state elasticity of demand. Note that in steady state an intermediate good firm sets price as a markup over marginal cost, where the markup, $\zeta$, is $\bar{\eta} /(\bar{\eta}-1)-1$. 
Many authors have considered the value of

$$
\epsilon=\left.\frac{P^{*}}{\eta(x)} \frac{\partial \eta(x)}{\partial P^{*}}\right|_{x=1} .
$$

This is the percent change in the elasticity of demand due to a one percent change in the own price at the steady state. The value of $\epsilon$ can be derived in terms of $A$ and $\bar{\eta}$ (or $\zeta$ ) using (2), (35), (36), and (37)

$$
\epsilon=\left[\frac{P^{*}}{\eta(x)} \frac{\partial \eta(x)}{\partial x} \frac{\partial x}{\partial \tilde{Y}} \frac{\partial \tilde{Y}}{\partial P^{*}}\right]_{x=1}=1+\bar{\eta}\left[\frac{1-1 / \bar{\eta}}{A}-1\right]=1+\frac{1+\zeta}{\zeta}\left[\frac{1}{(1+\zeta) A}-1\right] .
$$

Notice that under Dixit-Stiglitz, when $A=1, \epsilon=0$. This is to be expected: under DixitStiglitz, the markup is constant. Solving for $A$ using the last equality in the above expression, we find

$$
A=\frac{1}{\zeta \epsilon+1} .
$$

\section{Firm-Specific Capital with the Kimball Specification}

In this section we describe the solution to the model with firm-specific capital and the Kimball specification of the final good technology. Our derivation follows Christiano (2004) and Woodford (2004), who consider firm- specific capital with the Dixit-Stiglitz specification. The model is identical to the one described in section 2.1 except that, in addition to the usual Calvo price-setting, at each date $t-\tau$ all intermediate good firms choose date $t+1$ capital subject to adjustment costs. ${ }^{20}$ Labor continues to be hired in economy-wide competitive labor markets. Firms take all aggregate variables as given, including the return on risk-free one-period real bonds, $R_{t}$. Below we focus on the static indexation case. The derivation under dynamic indexation is similar.

The objective of a randomly chosen intermediate firm $i$ at date $t-\tau$, before it knows whether it can re-optimize its price, is to maximize the expected present value of profit:

$$
E_{t-\tau} \sum_{j=0}^{\infty} \Lambda_{t+j}\left[P_{i, t+j} Y_{i, t+j}-W_{t+j} Y_{i, t+j}^{1 /(1-\alpha)} A_{t+j}^{-1 /(1-\alpha)} K_{i, t+j}^{-\alpha /(1-\alpha)}-P_{t+j} I_{i, t+j}\right]
$$

subject to (2) and (15). Here $\Lambda_{t+j}=\prod_{l=0}^{\infty} \pi_{t+j+1} / R_{t+j}$ and $I_{t+j}$ is the investment of the $i$ 'th intermediate firm. In (38), we have substituted out for labor using the production function. Also, we have assumed, without loss of generality, that the price of investment goods is the same as that for consumption.

Marginal cost at firm $i$ is given by

$$
s_{i t}=\frac{W_{t}}{P_{t}} \frac{1}{(1-\alpha) Z_{t} K_{i t}^{\alpha} H_{i t}^{-\alpha}} .
$$

\footnotetext{
${ }^{20}$ In practice we only require that it be made at least $\tau$ periods before date $t$. Assuming otherwise complicates the analysis in a manner described below.
} 
Linearizing average marginal cost, $s_{t}=\int_{0}^{1} s_{i t} d i$, we find

$$
\begin{aligned}
\hat{s}_{t} & =\int_{0}^{1} \hat{s}_{i, t} d i \\
& =\hat{W}_{t+j}-\hat{P}_{t+j}-\frac{1}{1-\alpha} \hat{A}_{t+j}+\frac{\alpha}{1-\alpha} \hat{Y}_{t+j}-\frac{\alpha}{1-\alpha} \hat{K}_{t} .
\end{aligned}
$$

It follows that

$$
\hat{s}_{i t}=\hat{s}_{t}+\frac{\alpha}{1-\alpha}\left[\hat{Y}_{i t}-\hat{Y}_{t}\right]-\frac{\alpha}{1-\alpha}\left[\hat{K}_{i t}-\hat{K}_{t}\right] .
$$

Linearizing the first order condition associated with the price choice (in the event that it can re-optimize its price) and substituting for real marginal cost of firm $i, \hat{s}_{i t}$ :

$$
\hat{E}_{t-\tau}^{i} \sum_{j=0}^{\infty}(\beta \theta)^{j}\left[(1+\xi A \bar{\eta}) \hat{p}_{i t+j}-A \hat{s}_{t+j}+\xi A \hat{k}_{i t+j}\right]=0
$$

where $A$ is defined in $(9), \hat{k}_{i t} \equiv\left[\hat{K}_{i t}-\hat{K}_{t}\right], \xi \equiv \alpha /(1-\alpha), p_{i t+j} \equiv P_{i t+j} / P_{t+j}$, and $\widehat{x}$ denotes percent deviation of $x$ from its steady state value. Also, $\hat{E}_{t-\tau}^{i} X_{i t+k}$ denotes the expectation of the random variable $X_{i t+k}$, conditional on date $t-\tau$ information and on the event that the $i$ 'th firm optimizes its price in period $t$, but not in any period after that, up to and including $t+k$.

Linearizing the first order condition for the choice of $t+1$ capital (regardless of whether the firm can reoptimize its price or not)

$$
E_{t-\tau}\left[Q(L) \hat{k}_{i t+2}\right]=\Xi E_{t-\tau} \hat{p}_{i t+1}
$$

where

$$
\begin{aligned}
Q(L) & =\beta-\phi L+L^{2} \\
\phi & =1+\beta+(1-\beta(1-\delta)) \frac{1}{1-\alpha} \frac{1}{\psi}, \\
\Xi & =(1-\beta(1-\delta)) \bar{\eta} \frac{1}{1-\alpha} \frac{1}{\psi} .
\end{aligned}
$$

Here $L$ is the lag operator. Also, $E_{t-\tau}$ denotes the expectation operator, conditional on date $t-\tau$ information, where the expectation integrates over all possible continuation histories associated with the date $t-\tau$ information, including histories in which firm $i$ reoptimizes its price. A comparable expression is derived in Woodford (2003, p. 689).

Linearizing the zero profit condition for final good producers yields

$$
\hat{\pi}_{t}=\frac{1-\theta}{\theta} \hat{p}_{t}^{*}
$$

Here, $\hat{p}_{t}^{*}$ is the percent deviation from steady state of the average optimized relative price set in period $t$.

Following Christiano (2004) and Woodford (2004), we solve (39) and (40) using the 
method of undetermined coefficients and combine this solution with (41) to derive the reduced form inflation equation. We posit that the price chosen by price-optimizing firms is:

$$
\hat{p}_{i t}^{*}=\hat{p}_{t}^{*}-\nu \hat{k}_{i t},
$$

where $\nu$ is a number to be determined and $\hat{p}_{t}^{*}$ is a function of aggregate variables only, which is also to be determined. Note that, according to our assumptions, the variables on the right hand side of (42) are known when the price decision is made at $t-\tau$. The capital decision of a firm is assumed to satisfy:

$$
\hat{k}_{i t+1}=\kappa_{1} \hat{k}_{i t}+\kappa_{2} E_{t-\tau} \hat{p}_{i t}
$$

where $\kappa_{1}$ and $\kappa_{2}$ are to be determined. Here, the variable $\hat{p}_{i t}$ denotes the $i$ 'th firm's price, whether optimized or not. If the firm is not reoptimizing at date $t-\tau$, then $\hat{p}_{i t}$ is not in the information set used to choose $\hat{k}_{i t+1}$. This is why we have $E_{t-\tau}$ in (43).

The requirement that (42) and (43) must be satisfied for all possible realizations of $\hat{p}_{t}^{*}, \hat{k}_{i t}$ and $E_{t-\tau} \hat{p}_{i t}$ implies the unknown coefficients, $\kappa_{1}, \kappa_{2}$ and $\nu$ must satisfy the following three equations, subject to $\left|\kappa_{1}\right|<1$ :

$$
\begin{aligned}
1-\left[\phi+(1-\theta) \nu\left(\beta \kappa_{2}-\Xi\right)\right] \kappa_{1}+\beta \kappa_{1}^{2} & =0 \\
\Xi \theta+\left[\phi-\beta\left(\theta+\kappa_{1}\right)-(1-\theta) \Xi \nu\right] \kappa_{2}+\beta(1-\theta) \nu \kappa_{2}^{2} & =0 \\
\frac{\xi A(1-\beta \theta)}{(1+\bar{\eta} \xi A)\left(1-\beta \theta \kappa_{1}\right)+\xi A \beta \theta \kappa_{2}}-\nu & =0 .
\end{aligned}
$$

Christiano (2004) incorporates industry-specific labor in this model. Except for this difference, these three equations are equivalent to analogous equations he derives under the assumption of a constant elasticity of demand, $A=1$.

Following Christiano (2004), we can derive an expression for $\hat{p}_{t}^{*}$ using the linearized first order conditions as well as (42) and (43):

$$
\hat{p}_{t}^{*}=\sum_{j=1}^{\infty}(\beta \theta)^{j} E_{t-\tau} \hat{\pi}_{t+j}+\frac{\left(1-\beta \theta \kappa_{1}\right)(1-\beta \theta)}{(1+\bar{\eta} \xi A)\left(1-\beta \theta \kappa_{1}\right)+\xi A \beta \theta \kappa_{2}} \sum_{j=0}^{\infty}(\beta \theta)^{j} E_{t-\tau} \hat{s}_{t+j} .
$$

By substituting this expression into (41), we obtain the following equation relating inflation to average marginal cost:

$$
\hat{\pi}_{t}=\beta E_{t-\tau} \hat{\pi}_{t+1}+\frac{1-\theta}{\theta}(1-\beta \theta) A \cdot D E_{t-\tau} \hat{s}_{t}
$$

where

$$
D=\frac{\left(1-\beta \theta \kappa_{1}\right)}{(1+\bar{\eta} \xi A)\left(1-\beta \theta \kappa_{1}\right)+\xi A \beta \theta \kappa_{2}} .
$$

When adjustment costs go to infinity, that is as $\psi \rightarrow \infty$, then $\kappa_{1} \rightarrow 1$ and $\kappa_{2} \rightarrow 0$. In this case it is easy to see that

$$
D \rightarrow \frac{1}{1+\bar{\eta} \xi A}
$$


Under Dixit-Stiglitz, $A=1$ and $\bar{\eta}=\mu$, in which case $D$ corresponds to the coefficient derived by Sbordone (2002) for her model of constant capital.

When there are no adjustment costs $(\psi=0)$ it is easy to verify that

$$
\kappa_{1}=0, \quad \kappa_{2}=-\tilde{\Xi} / \tilde{\phi}, \quad \nu=\xi A(1-\beta \theta) /\left[(1+\bar{\eta} \xi A)+\xi A \beta \theta \kappa_{2}\right]
$$

where $\tilde{\Xi}=(1-\beta(1-\delta)) \bar{\eta} /(1-\alpha)$ and $\tilde{\phi}=1+\beta+(1-\beta(1-\delta)) /(1-\alpha)$. In this case

$$
D=\frac{1}{(1+\bar{\eta} \xi A)-\xi A \beta \theta \tilde{\Xi} / \tilde{\phi}} .
$$

\section{Interpreting the Adjustment Cost Parameter, $\psi$}

In the model without capital rental markets, what is an empirically plausible value for the capital adjustment cost parameter, $\psi$ ? Typically, the magnitude of capital adjustment costs is assessed by considering its implications for the elasticity of the investment-capital ratio with respect to Tobin's $q$. To do this in our model, we assume the existence of a competitive stock market in which claims on the profits of intermediate good firms are traded. Under our assumptions, in general, intermediate good firms will be valued differently.

Tobin's $q$ for firm $i$ is defined as

$$
q_{i t}=\frac{P_{K_{i}^{\prime} t}}{P_{I t}}
$$

where $P_{K_{i}^{\prime} t}$ denotes the marginal value of capital at firm $i$ installed at the beginning of time $t+1$ and $P_{I t}$ is the price of investment goods, which is unity, since investment and consumption goods are both derived from the composite final good. Profit maximization implies the value of a marginal unit of installed capital is equal to its cost. That is,

$$
P_{K^{\prime} t}=\frac{P_{I, t}}{M P I_{t}}=\frac{1}{M P I_{t}}
$$

where $M P I_{t}=d K_{i t+1} / d I_{t}$ is the marginal product of investment in producing installed date $t=1$ capital. The marginal product of investment can be derived by differentiating equation (15). Under the assumption that $K_{i, t}$ is predetermined at date $t$ this yields $d K_{i t+1} / d\left(I_{i t} / K_{i t}\right)=K_{i t} / Q^{\prime}\left(K_{i t+1} / K_{i t}\right)$. It follows that

$$
q_{i t}=\frac{Q^{\prime}\left(\frac{K_{i t+1}}{K_{i t}}\right)}{K_{i t}} .
$$

The desired elasticity may be derived by differentiation of (44) and (15). Differentiating (44) yields $d K_{i t+1} / d q_{i t}=K_{i t} / Q^{\prime \prime}\left(K_{i t+1} / K_{i t}\right)$ and (15) implies $d\left(I_{i t} / K_{i t}\right) / d K_{i t+1}=$ $Q^{\prime}\left(K_{i t+1} / K_{i t}\right) / K_{i t}$. Therefore, the elasticity of $I_{i t} / K_{i t}$ with respect to $q_{i t}$ is

$$
\frac{q_{i t}}{I_{i t} / K_{i t}} \frac{d\left(I_{i t} / K_{i t}\right)}{d q_{i t}}=\frac{q_{i t}}{I_{i t} / K_{i t}} \frac{\partial I_{i t} / K_{i t}}{\partial K_{i t+1}} \cdot \frac{\partial K_{i t+1}}{\partial q_{i t}}=\frac{q_{i t}}{I_{i t} / K_{i t}} \frac{Q^{\prime}\left(\frac{K_{i t+1}}{\left.K_{i t}\right)}\right.}{\left.Q_{i t+1}\right)} .
$$


Evaluating the expression on the right hand side of the second equality above in steady state,

$$
\frac{q}{I / K} \frac{d(I / K)}{\partial q}=\frac{1}{\delta \psi},
$$

where we have dropped subscripts to denote steady state values of variables. Equation (45) follows since $Q^{\prime}(1)=1, Q^{\prime \prime}(1)=\psi, q=1$ and $I / K=\delta$. 
Table 1. Estimates of the Standard Model with Static Indexing

\begin{tabular}{lllll} 
Inflation & \multicolumn{2}{c}{$L=0$} & \multicolumn{2}{c}{$L=12$} \\
Measure & $\theta$ & \multicolumn{1}{c}{$J_{T}$} & $\theta$ & $J_{T}$ \\
& \multicolumn{4}{c}{$1959: \mathrm{I}-2001: \mathrm{IV}$} \\
GDP Deflator & 0.90 & 28.2 & 0.91 & 10.2 \\
& $(0.05)$ & {$[9 \mathrm{e}-5]$} & $(0.03)$ & {$[0.04]$} \\
PCE Deflator & 0.87 & 36.9 & 0.88 & 11.1 \\
& $(0.04)$ & {$[2 \mathrm{e}-6]$} & $(0.02)$ & {$[0.03]$} \\
& \multicolumn{4}{c}{$1959: \mathrm{I}-1979: \mathrm{II}$} \\
& & \\
GDP Deflator & 0.86 & 12.1 & 0.87 & 4.58 \\
& $(0.05)$ & {$[0.02]$} & $(0.03)$ & {$[0.33]$} \\
PCE Deflator & 0.82 & 16.8 & 0.83 & 5.60 \\
& $(0.04)$ & {$[0.02]$} & $(0.02)$ & $(0.23)$ \\
& \multicolumn{4}{c}{$1982: \mathrm{III}-2001: \mathrm{IV}$} \\
GDP Deflator & 0.87 & 15.8 & 0.90 & 6.16 \\
& $(0.04)$ & {$[0.003]$} & $(0.03)$ & {$[0.19]$} \\
PCE Deflator & 0.87 & 8.89 & 0.89 & 4.39 \\
& $(0.04)$ & {$[0.06]$} & $(0.03)$ & {$[0.36]$}
\end{tabular}

Notes: The $J_{T}$ statistics are distributed as $\chi^{2}$ random variables with 4 degrees of freedom. Standard errors in parentheses. P-values in brackets. In the $L=12$ cases, the Newey-West correction to the weighting matrix is used. 
Table 2. Estimates of the Standard model with Dynamic Indexing

\begin{tabular}{lllll} 
Inflation & \multicolumn{2}{c}{$L=0$} & \multicolumn{2}{c}{$L=12$} \\
Measure & $\theta$ & \multicolumn{1}{c}{$J_{T}$} & \multicolumn{4}{c}{$J_{T}$} \\
& \multicolumn{4}{c}{$1959: \mathrm{I}-2001: \mathrm{IV}$} \\
GDP Deflator & 0.81 & 35.0 & 0.91 & 10.2 \\
& $(0.03)$ & {$[6 \mathrm{e}-7]$} & $(0.02)$ & {$[0.04]$} \\
PCE Deflator & 0.79 & 47.9 & 0.88 & 10.8 \\
& $(0.03)$ & {$[1 \mathrm{e}-9]$} & $(0.02)$ & {$[0.03]$} \\
& \multicolumn{4}{c}{$1959: \mathrm{I}-1979: \mathrm{II}$} \\
& & \\
GDP Deflator & 0.76 & 17.5 & 0.87 & 5.59 \\
& $(0.05)$ & {$[0.002]$} & $(0.04)$ & {$[0.23]$} \\
PCE Deflator & 0.77 & 18.1 & 0.88 & 5.80 \\
& $(0.04)$ & {$[0.002]$} & $(0.03)$ & $(0.22)$ \\
& \multicolumn{4}{c}{$1982: \mathrm{III}-2001: \mathrm{IV}$} \\
GDP Deflator & 0.68 & 17.0 & 0.83 & 4.41 \\
& $(0.04)$ & {$[0.002]$} & $(0.08)$ & {$[0.35]$} \\
PCE Deflator & 0.54 & 14.2 & 0.77 & 4.54 \\
& $(0.03)$ & {$[0.007]$} & $(0.06)$ & {$[0.34]$}
\end{tabular}

Notes: The $J_{T}$ statistics are distributed as $\chi^{2}$ random variables with 3 degrees of freedom. Standard errors in parentheses. P-values in brackets. In the $L=12$, cases the Newey-West correction to the weighting matrix is used. 
Table 3: Prices Chosen One Period In Advance with Static Indexing

\begin{tabular}{lllllll} 
Inflation & \multicolumn{2}{c}{ Full Sample } & \multicolumn{2}{l}{ 1959:I-1979:II } & \multicolumn{2}{l}{ 1982:III-2001:IV } \\
Measure & $\theta$ & $J_{T}$ & $\theta$ & $J_{T}$ & $\theta$ & $J_{T}$ \\
\hline GDP Deflator & 0.89 & 6.89 & 0.84 & 2.96 & 0.92 & 3.98 \\
& $(0.03)$ & {$[0.14]$} & $(0.03)$ & {$[0.56]$} & $(0.04)$ & {$[0.41]$} \\
PCE Deflator & 0.90 & 8.54 & 0.83 & 2.95 & 0.91 & 3.50 \\
& $(0.03)$ & {$[0.07]$} & $(0.05)$ & {$[0.56]$} & {$[0.05]$} & {$[0.48]$}
\end{tabular}

Notes: The $J_{T}$ statistics are distributed as $\chi^{2}$ random variables with 3 degrees of freedom. Standard errors in parentheses. P-values in brackets.

Table 4: Prices Chosen One Period In Advance with Dynamic Indexing

\begin{tabular}{lllllll} 
Inflation & \multicolumn{2}{c}{ Full Sample } & \multicolumn{2}{l}{ 1959:I-1979:II } & \multicolumn{2}{l}{ 1982:III-2001:IV } \\
Measure & $\theta$ & $J_{T}$ & $\theta$ & $J_{T}$ & $\theta$ & $J_{T}$ \\
\hline GDP Deflator & 0.88 & 2.65 & 0.86 & 0.89 & 0.83 & 6.33 \\
& $(0.05)$ & {$[0.62]$} & $(0.09)$ & {$[0.93]$} & $(0.05)$ & {$[0.18]$} \\
PCE Deflator & 0.86 & 4.98 & 0.84 & 2.05 & 0.83 & 5.61 \\
& $(0.05)$ & {$[0.29]$} & $(0.08)$ & {$[0.73]$} & $(0.06)$ & {$[0.23]$}
\end{tabular}

Notes: This table considers the case where firms that do not reset their price plans use the updating scheme: $P_{i t}=\pi_{t-1} P_{i t-1}$. The $J_{T}$ statistics are distributed as $\chi^{2}$ random variables with 3 degrees of freedom. Standard errors in parentheses. P-values in brackets.

Table 5: Prices Chosen One Period In Advance, Static Indexing, and Rule of Thumb Firms

\begin{tabular}{llllllllll} 
Inflation & \multicolumn{3}{c}{ Full Sample } & \multicolumn{3}{c}{ 1959:I-1979:II } & \multicolumn{3}{c}{ 1982:III-2001:IV } \\
Measure & $\theta$ & $\omega$ & $J_{T}$ & $\theta$ & $\omega$ & $J_{T}$ & $\theta$ & $\omega$ & $J_{T}$ \\
\hline GDP Deflator & 0.85 & 0.44 & 0.92 & 0.88 & 0.51 & 0.68 & 0.85 & 0.37 & 0.73 \\
& $(0.08)$ & $(0.17)$ & {$[0.82]$} & $(0.11)$ & $(0.32)$ & {$[0.97]$} & $(0.12)$ & $(0.28)$ & {$[0.87]$} \\
PCE Deflator & 0.96 & 0.56 & 1.66 & 0.97 & 0.72 & 0.73 & 0.48 & 0.80 & 0.12 \\
& $(0.09)$ & $(0.22)$ & {$[0.64]$} & $(0.09)$ & $(0.35)$ & {$[0.87]$} & $(0.18)$ & $(0.08)$ & {$[0.99]$}
\end{tabular}

Notes: This table considers the case where $(1-\omega)$ of firms that have the opportunity to change prices do so optimally, while $\omega$ are of the Gali-Gertler type; that is, they set prices according to $P_{t}^{\prime}=\pi_{t-1} \bar{P}_{t-1}$. where $\bar{P}_{t}=(1-\omega) P_{t}^{*}+\omega P_{t}^{\prime}$. When unable to reset the price plan, all firms use the same updating scheme, $P_{i t}=\bar{\pi} P_{i t-1}$. The $J_{T}$ statistics are distributed as $\chi^{2}$ random variables with 3 degrees of freedom. Standard errors in parentheses. P-values in brackets. 
Table 6: Prices Chosen One Period In Advance,

Dynamic Indexing, and Rule of Thumb Firms

\begin{tabular}{llllllllll} 
Inflation & \multicolumn{3}{c}{ Full Sample } & \multicolumn{3}{c}{ 1959:I-1979:II } & \multicolumn{3}{c}{ 1982:III-2001:IV } \\
Measure & $\theta$ & $\omega$ & $J_{T}$ & $\theta$ & $\omega$ & $J_{T}$ & $\theta$ & $\omega$ & $J_{T}$ \\
\hline GDP Deflator & 0.87 & 0.04 & 2.79 & 0.83 & 0.12 & 0.61 & 0.82 & 0.15 & 6.12 \\
& $(0.05)$ & $(0.14)$ & {$[0.43]$} & $(0.10)$ & $(0.22)$ & {$[0.89]$} & $(0.07)$ & $(0.26)$ & {$[0.11]$} \\
PCE Deflator & 0.88 & -0.06 & 4.79 & 0.85 & -0.02 & 1.85 & 0.76 & 0.40 & 5.67 \\
& $(0.06)$ & $(0.15)$ & {$[0.19]$} & $(0.09)$ & $(0.18)$ & {$[0.60]$} & $(0.63)$ & $(2.73)$ & {$[0.13]$}
\end{tabular}

Notes: This table considers the case where $(1-\omega)$ of firms that have the opportunity to change prices do so optimally and use dynamic indexing when they do not have the opportunity to reset the price plan. In addition, $\omega$ firms are of the type Gali-Gertler considered in their paper. That is, they set prices $P_{i t}^{\prime}$ according to $P_{i t}^{\prime}=\pi_{t-1} \bar{P}_{t-1}$, where $\bar{P}_{t}=(1-\omega) P_{t}^{*}+\omega P_{t}^{\prime}$ when they have the opportunity to reset their plan, but use $P_{i t}=\bar{\pi} P_{i t-1}$. The $J_{T}$ statistics are distributed as $\chi^{2}$ random variables with 3 degrees of freedom. Standard errors in parentheses. P-values in brackets.

Table 7: Frequency of Reoptimization with Prices Chosen One Period in Advance and Dynamic Indexing: Full Sample Results

\begin{tabular}{|c|c|c|c|c|c|c|c|}
\hline \multirow[b]{3}{*}{ Deflator } & \multirow[b]{3}{*}{$\epsilon$} & \multirow{2}{*}{\multicolumn{2}{|c|}{$\begin{array}{l}\text { Rental Market } \\
\text { for Capital }\end{array}$}} & \multicolumn{4}{|c|}{ Firm-Specific Capital } \\
\hline & & & & \multicolumn{2}{|c|}{$\psi=0$} & \multicolumn{2}{|c|}{$\psi=3$} \\
\hline & & $\theta$ & $\frac{1}{1-\theta}$ & $\theta$ & $\frac{1}{1-\theta}$ & $\theta$ & $\frac{1}{1-\theta}$ \\
\hline \multirow[t]{6}{*}{ GDP } & 0 & 0.88 & 8.3 & 0.83 & 5.9 & 0.72 & 3.6 \\
\hline & & {$[0.78,0.98]$} & {$[4.5,50.0]$} & {$[0.65,0.97]$} & {$[2.9,33.3]$} & {$[0.53,0.95]$} & {$[2.1,20.0]$} \\
\hline & 10 & 0.83 & 5.9 & 0.79 & 4.8 & 0.70 & 3.3 \\
\hline & & {$[0.70,0.96]$} & {$[3.3,25.0]$} & {$[0.60,0.96]$} & {$[2.5,25.0]$} & {$[0.51,0.94]$} & {$[2.0,16.7]$} \\
\hline & 33 & 0.76 & 4.2 & 0.72 & 3.6 & 0.66 & 2.9 \\
\hline & & {$[0.60,0.95]$} & {$[2.5,20.0]$} & {$[0.52,0.94]$} & {$[2.1,16.7]$} & {$[0.46,0.93]$} & {$[1.9,14.3]$} \\
\hline \multirow[t]{6}{*}{ PCE } & 0 & 0.86 & 7.1 & 0.80 & 5.0 & 0.69 & 3.2 \\
\hline & & {$[0.77,0.96]$} & {$[4.3,25.0]$} & {$[0.62,0.95]$} & {$[2.6,20.0]$} & {$[0.51,0.91]$} & {$[2.0,11.0]$} \\
\hline & 10 & 0.81 & 5.3 & 0.76 & 4.2 & 0.67 & 3.0 \\
\hline & & {$[0.68,0.94]$} & {$[3.1,16.7]$} & {$[0.57,0.93]$} & {$[2.3,14.3]$} & {$[0.49,0.90]$} & {$[2.0,10.0]$} \\
\hline & 33 & 0.73 & 3.7 & 0.69 & 3.2 & 0.63 & 2.7 \\
\hline & & {$[0.57,0.91]$} & {$[2.3,11.1]$} & {$[0.49,0.91]$} & {$[2.0,11.1]$} & {$[0.44,0.88]$} & {$[1.8,8.3]$} \\
\hline
\end{tabular}

Note: Estimates based on labor's share equal to $2 / 3$, a $10 \%$ markup and a $2.5 \%$ quarterly depreciation rate. 
Table 8: Frequency of Reoptimization with Prices Chosen One Period in Advance and Dynamic Indexing: Sub-Sample Results

Rental Market

Panel A: 1959:I-1979:II

\begin{tabular}{|c|c|c|c|c|c|c|c|}
\hline \multirow[b]{3}{*}{ Deflator } & \multirow[b]{3}{*}{$\epsilon$} & \multirow{2}{*}{\multicolumn{2}{|c|}{$\begin{array}{l}\text { Rental Market } \\
\text { for Capital }\end{array}$}} & \multicolumn{4}{|c|}{ Firm-Specific Capital } \\
\hline & & & & & & & \\
\hline & & $\theta$ & $\frac{1}{1-\theta}$ & $\theta$ & $\frac{1}{1-\theta}$ & $\theta$ & $\frac{1}{1-\theta}$ \\
\hline \multirow[t]{6}{*}{ GDP } & 0 & 0.86 & 7.1 & 0.79 & 4.8 & 0.67 & 3.0 \\
\hline & & {$[0.73,0.98]$} & {$[3.7,50.0]$} & {$[0.56,0.98]$} & {$[2.3,50.0]$} & {$[0.45,0.96]$} & {$[1.8,25.0]$} \\
\hline & 10 & 0.80 & 5.0 & 0.75 & 4.0 & 0.65 & 2.9 \\
\hline & & {$[0.64,0.97]$} & {$[2.8,33.3]$} & {$[0.50,0.97]$} & {$[2.0,33.3]$} & {$[0.43,0.96]$} & {$[1.8,25.0]$} \\
\hline & 33 & 0.72 & 3.6 & 0.68 & 3.1 & 0.61 & 2.6 \\
\hline & & {$[0.52,0.96]$} & {$[2.1,25.0]$} & {$[0.43,0.96]$} & {$[1.8,20.0]$} & {$[0.38,0.94]$} & {$[1.6,16.7]$} \\
\hline \multirow[t]{6}{*}{ PCE } & 0 & 0.84 & 6.3 & 0.80 & 5.0 & 0.65 & 2.9 \\
\hline & & {$[0.75,0.94]$} & {$[4.0,16.7]$} & {$[0.62,0.95]$} & {$[2.6,20.0]$} & {$[0.48,0.89]$} & {$[1.9,9.1]$} \\
\hline & 10 & 0.78 & 4.6 & 0.76 & 4.2 & 0.63 & 2.7 \\
\hline & & {$[0.66,0.91]$} & {$[2.9,11.1]$} & {$[0.57,0.93]$} & {$[2.3,14.3]$} & {$[0.46,0.86]$} & {$[1.9,6.7]$} \\
\hline & 33 & 0.70 & 3.3 & 0.69 & 3.2 & 0.59 & 2.4 \\
\hline & & {$[0.55,0.87]$} & {$[2.2,7.7]$} & {$[0.49,0.91]$} & {$[2.0,11.1]$} & {$[0.41,0.82]$} & {$[1.7,5.6]$} \\
\hline
\end{tabular}

Panel B: 1982:III-2001:IV

Rental Market

Firm-Specific Capital

for Capital

\begin{tabular}{lccccccc} 
Deflator & $\epsilon$ & $\theta$ & $\frac{1}{1-\theta}$ & $\theta$ & $\frac{1}{1-\theta}$ & $\theta$ & $\frac{1}{1-\theta}$ \\
\hline GDP & $\mathbf{0}$ & $\mathbf{0 . 8 3}$ & $\mathbf{5 . 9}$ & $\mathbf{0 . 7 5}$ & $\mathbf{4 . 0}$ & $\mathbf{0 . 6 3}$ & $\mathbf{2 . 7}$ \\
& & {$[0.73,0.93]$} & {$[3.7,14.3]$} & {$[0.56,0.92]$} & {$[2.3,12.5]$} & {$[0.45,0.85]$} & {$[1.8,6.7]$} \\
& $\mathbf{1 0}$ & $\mathbf{0 . 7 7}$ & $\mathbf{4 . 4}$ & $\mathbf{0 . 7 0}$ & $\mathbf{3 . 3}$ & $\mathbf{0 . 6 0}$ & $\mathbf{2 . 5}$ \\
& & {$[0.64,0.90]$} & {$[2.8,10.0]$} & {$[0.51,0.90]$} & {$[2.0,10.0]$} & {$[0.43,0.84]$} & {$[1.8,6.2]$} \\
& $\mathbf{3 3}$ & $\mathbf{0 . 6 8}$ & $\mathbf{3 . 1}$ & $\mathbf{0 . 6 2}$ & $\mathbf{2 . 6}$ & $\mathbf{0 . 5 6}$ & $\mathbf{2 . 3}$ \\
& & {$[0.52,0.86]$} & {$[2.1,7.1]$} & {$[0.43,0.85]$} & {$[1.8,6.7]$} & {$[0.38,0.81]$} & {$[1.6,5.3]$}
\end{tabular}

PCE

$\begin{array}{ccccccc}\mathbf{0} & \mathbf{0 . 8 3} & \mathbf{5 . 9} & \mathbf{0 . 8 0} & \mathbf{5 . 0} & \mathbf{0 . 6 3} & \mathbf{2 . 7} \\ & {[0.71,0.95]} & {[3.5,20.0]} & {[0.62,0.95]} & {[2.6,20.0]} & {[0.43,0.91]} & {[1.8,11.1]} \\ \mathbf{1 0} & \mathbf{0 . 7 7} & \mathbf{4 . 4} & \mathbf{0 . 7 6} & \mathbf{4 . 2} & \mathbf{0 . 6 0} & \mathbf{2 . 5} \\ & {[0.62,0.92]} & {[2.6,12.5]} & {[0.57,0.93]} & {[2.3,14.3]} & {[0.41,0.89]} & {[1.7,9.1]} \\ \mathbf{3 3} & \mathbf{0 . 6 8} & \mathbf{3 . 1} & \mathbf{0 . 6 9} & \mathbf{3 . 2} & \mathbf{0 . 5 6} & \mathbf{2 . 3} \\ & {[0.50,0.89]} & {[2.0,9.1]} & {[0.49,0.91]} & {[2.0,11.1]} & {[0.36,0.85]} & {[1.6,6.7]}\end{array}$

Note: Estimates based on labor's share equal to $2 / 3$, a $10 \%$ markup, and a $2.5 \%$ quarterly depreciation rate. 